\title{
Ecos de uma perspectiva crítica na formação universitária de professores de línguas .
}

\author{
Dllubia Santclair (SEDUC - GO/UNB) ${ }^{l}$ \\ Kleber Silva $(U N B)^{2}$
}

\begin{abstract}
Resumo : Este artigo apresenta a análise de um curso de Letras português/inglês da Universidade Estadual de Goiás, com a finalidade de refletir sobre a perspectiva crítica na formação universitária de professores/as de línguas. $O$ estudo surge de alguns questionamentos: o que é uma perspectiva crítica na formação de professores de línguas? Qual é a concepção de língua para essa perspectiva? Os documentos que direcionam o curso apresentam elementos alinhados aos princípios críticos? Quais as percepções dos professores em formação universitária? Partindo do pressuposto que é fundamental envolver professores/as em formação universitária em um fazer pedagógico crítico, conectado à diversidade cultural e linguística, buscamos identificar as políticas que norteiam esse curso e compreender como ecoam os princípios da linguística aplicada crítica nas vozes dos participantes de pesquisa. Nesse sentido, a partir de um estudo de caso, propomos uma articulação dessas políticas à epistemologia crítica defendida por Pennycook $(2001,2018)$, Pessoa (2019) e Urzêda-Freitas e Pessoa (2012). Compreendemos que para se pensar uma formação crítica é preciso partir de uma concepção de língua como instrumento de transformação social e essa concepção deve se apresentar nos documentos norteadores, nas escolhas dos textos e na praxis.
\end{abstract}

Palavras-chave: Formação universitária, Perspectiva crítica, Professores/as de línguas

\section{Introdução}

Desde meados da década de 90, pesquisadores têm se debruçado sobre o tema central deste estudo. Muitas publicações foram feitas na tentativa de explicitar a Linguística Aplicada Crítica (LAC): a perspectiva crítica para o processo de ensino-aprendizagem e a formação de professores, com uma grande contribuição de Pennycook (1990; 2001; 2018).

1 Doutoranda em Linguística pela Universidade de Brasília (UNB). Professora na Secretaria de Estado da Educação de Goiás (Seduc GO).E-mail: dllubiasantclair@gmail.com

2 Pós doutor, professor e pesquisador na Universidade de Brasília (UNB).E-mail: Kleberunicamp@yahoo.com.br 
Interessa-nos compreender o delineamento da perspectiva crítica na formação universitária de professores/as de línguas em território goiano. Portanto, o estudo que apresentamos é o resultado de uma investigação maior em que o foco é os diálogos interculturais nas aulas de inglês ${ }^{3}$ no contexto do curso de Letras português/inglês. Por meio das interações observadas entre sete acadêmicos e seu professor, percebemos os ecos nos discursos dos participantes que ressoam práticas democratizadoras de reflexão sobre o mundo em que vivemos, a instituição da qual fazemos parte e alimentamos nossos anseios (PENNYCOOK, 2018).

Por se tratar de uma pesquisa qualitativa interpretativista, optamos por organizar o texto da seguinte forma: em primeiro lugar, trazemos contribuições teóricas para o entendimento da perspectiva crítica na formação de professores, seguida pelo caminho histórico-legal dos cursos de licenciatura dupla no país e, na sequência, apresentamos o contexto goiano em que este estudo foi realizado e discutimos o Projeto Político Pedagógico do Curso. Em seguida, apresentamos questões teóricas em relação ao construto língua, entrelaçadas à análise do recorte dos dados escolhidos para este estudo.

\section{Perspectiva crítica na formação de professores}

Iniciamos essa sessão apresentando nossa compreensão sobre o que é formar um professor de línguas em uma perspectiva crítica. Esse entendimento perpassa pela concepção de língua que adotamos, uma vez que é por meio da língua, do uso linguístico que desigualdades são disseminadas e/ou perpetuadas.

A língua não pode ser compreendida somente como forma abstrata, mas como instrumento dialógico e social (BAKHTIN, 2011). Em tempos críticos, a língua é considerada um meio de produção e expressão daquilo que permeia a interação social (PENNYCOOK, 2001). Portanto, coadunamos com a definição apresentada por Urzêda-Freitas e Pessoa (2012, p.232), a língua "é uma ferramenta que produz e, ao mesmo tempo, reflete as relações socias".

3 Trata-se de uma dissertação (MATIAS, 2017), desenvolvida na Universidade Estadual de Goiás, sob a orientação da Professora Dra Barbra Sabota, a quem agradecemos pelas valiosas contribuições no texto produzido. Ressaltamos nossa responsabilidade pelas possiveis falhas remanescentes.

Gláuks: Revista de Letras e Artes-jan/jun. 2020 - Vol. 20, $N^{o} 1$ 
Nesse sentido, entender o poder de nossas práticas linguísticas pode nos permitir vislumbrar os ecos que temos ressoado na formação de professores de línguas.

Em relação à formação crítica, Pennycook, em seu livro $A$ critical applied linguistics: an introduction, lançado em 2001, já alertava e defendia a necessidade de prepararmos os alunos para repensar e ressignificar por meio da linguagem o modo como os saberes são construídos e isso reverbera na forma que suas vidas são constituídas. Esse posicionamento precisa estar expresso na construção do plano pedagógico do curso de formação de professores/as de línguas que esse aluno frequenta; nas escolhas textuais para as aulas, e se elas são impostas ou problematizadas.

Além do mais formar professores/as de línguas na perspectiva crítica é aprender sobre a língua em estudo e os elementos que a constituem e, principalmente, estar preparado para atuar em contextos diversos e múltiplos, criando possibilidades de comunicação que favoreçam as identidades sociais e a capacidade de se posicionar frente às colonialidades (QUIJANO, 1992).

Os estudos de Pessoa (2019, p. 174) mostram que formar professores/as de línguas é "problematizar esse mundo em que imperam desigualdades em todas as esferas sociais". Desse modo, a formação se constitui pelos questionamentos do que é legitimado, por quem, para quem e como ressignificamos essas perguntas no processo educacional.

Nessa busca por maneiras de ensinar e aprender na perspectiva crítica, a autora afirma adotar práticas de "negociação de sentidos sobre questões sociais, que é uma maneira de desenvolver competência em novos repertórios culturais.” (PESSOA, 2019, p. 178).

Diante dessas elucidações, perguntamos: é possível separar o professor em formação do contexto de ensino, das características dessa profissão, da grade curricular e de tantos outros elementos que permeiam essa formação? Portanto, tal questionamento nos permite entender que é fundamental apresentarmos como a licenciatura dupla se constitui no Brasil, discutir os seus desdobramentos no plano político pedagógico do curso investigado e problematizar os ecos discursivos dos participantes de pesquisa. 


\section{Panorama histórico-legal dos cursos de licenciatura dupla português/inglês}

O panorama aqui apresentado tem como base um levantamento feito pelos estudos de Matias (2017). É fundamental resgatarmos posicionamentos expressos nos documentos que regem a formação de professores/as de línguas e que podem nortear as práticas linguísticas em evidência na formação universitária.

A primeira proposta de currículo para os cursos de Letras foi aprovada em Outubro de 1962, pelo Conselho Federal de Educação, com o parecer nº 283 de Valnir Chagas. Até então, os currículos eram extensos e envolviam várias línguas com suas respectivas literaturas, resultando habilidades duvidosas para o exercício profissional. Esse texto legal previa apenas uma língua estrangeira para a licenciatura dupla e esta ocupava um status de língua menor, com caráter optativo (PAIVA, 2005).

Somente em outubro de 1969, com a resolução $n^{\circ}$ 9, foram incluídos itens referentes à formação pedagógica, conforme texto legal a seguir:

\footnotetext{
Art. $1^{\circ}$ - O currículo mínimo dos cursos que habilitem ao exercício do magistério, em escolas de $2^{\circ}$ grau, abrangerão as matérias de conteúdo fixadas em cada caso e as seguintes matérias pedagógicas: a) Psicologia da Educação; b) Didática; c) Estrutura e Funcionamento de Ensino de $2^{\circ}$ grau.

Art. $2^{\circ}$ - Será obrigatória a Prática de Ensino das matérias que sejam objeto de habilitação profissional, sob a forma de estágio supervisionado a desenvolver-se em situação real, de preferência em escola da comunidade.

Art. $3^{\circ}$ - A formação pedagógica prescrita nos artigos anteriores será ministrada em, pelo menos, um oitavo (1/8) das horas de trabalho fixadas, como duração mínima, para curso de licenciatura.

Art. $4^{\circ}$ - As disposições desta resolução terão vigência a partir do ano letivo de 1970, revogadas as disposições em contrário (BRASIL, 1969).
}

Apesar da preocupação pedagógica, não há uma atenção igualitária em relação à língua estrangeira, fato que gera prejuízos vivenciados até a atualidade, especialmente referentes à organização curricular baseada em disciplinas.

Paiva (2005) relata que, ao longo dos 34 anos em que esse currículo vigorou, participou de várias comissões de avaliação de condições de oferta de cursos de Letras designadas pela Secretaria de Educação Superior (SESU) - unidade do Ministério da Educação (MEC) e pôde constatar a insuficiência no número de horas reservadas para a língua estrangeira, bem como a falta de qualificação específica dos responsáveis pela formação do professor de LE. A autora afirma ainda que no biênio 1999-2000 foi constatado

Gláuks: Revista de Letras e Artes-jan/jun. 2020 - Vol. 20, $N^{o} 1$ 
que a formação docente dos cursos de Letras não incluía as reflexões teóricas e as atividades práticas necessárias para a formação desse profissional. Muitos cursos de Letras em português e inglês, desse período, eram ministrados em três anos, com poucas aulas do idioma, em turmas grandes e as aulas de literatura estrangeira ministradas em português.

$\mathrm{Na}$ atualidade, apesar de convivermos com resquícios dos problemas supracitados, na Lei de Diretrizes e Bases (LDB), de 1996, consta uma preocupação do MEC com a qualidade das licenciaturas. Houve a extinção da obrigatoriedade de currículos, instituindo, em seguida, as Diretrizes Curriculares Nacionais. Para melhor compreensão do leitor, sintetizamos no QUADRO 1, a seguir, os princípios, objetivos e metas que nortearam as Diretrizes Curriculares Nacionais para a Formação de Professores da Educação Básica (DCN - FPEB), em nível superior, curso de licenciatura, de graduação plena (BRASIL, 2002).

QUADRO 1 - Princípios, objetivos e metas das DCN - FPEB

Assegurar às instituições de ensino superior ampla liberdade na composição da carga horária a ser cumprida para a integralização dos currículos, assim como na especificação das unidades de estudos a serem ministradas;

Evitar o prolongamento desnecessário da duração dos cursos de graduação;

Indicar os tópicos ou campos de estudo e demais experiências de ensinoaprendizagem que comporão os currículos, evitando ao máximo a

Princípios fixação de conteúdos específicos com cargas horárias pré-determinadas, as quais não poderão exceder $50 \%$ da carga horária total dos cursos;

Incentivar uma sólida formação geral, necessária para que o futuro graduado possa vir a superar os desafios de renovadas condições de exercício profissional e de produção do conhecimento, permitindo variados tipos de formação e habilitações diferenciadas em um mesmo programa;

Estimular a prática de estudo independente, visando uma progressiva autonomia profissional e intelectual do aluno;

Encorajar o aproveitamento do conhecimento, habilidades e competências adquiridas fora do ambiente escolar, inclusive as que se referirem à experiência profissional julgada relevante para a área de formação considerada;

Fortalecer a articulação da teoria com a prática, valorizando a pesquisa individual e coletiva, assim como os estágios e a participação em atividades de extensão, as quais poderão ser incluídas como parte da carga horária; 


\begin{tabular}{|l|l|}
\hline \multirow{5}{*}{ Objetivos e e } & $\begin{array}{l}\text { Incluir orientações para a condução de avaliações periódicas que } \\
\text { utilizem instrumentos variados e sirvam para informar a docentes e a } \\
\text { discentes acerca do desenvolvimento das atividades didáticas. }\end{array}$ \\
\hline \multirow{5}{*}{ metas } & $\begin{array}{l}\text { Conferir maior autonomia às IES na definição dos currículos de seus } \\
\text { cursos, a partir da explicitação das competências e as habilidades que se } \\
\text { deseja desenvolver, através da organização de um modelo pedagógico } \\
\text { capaz de adaptar-se à dinâmica das demandas da sociedade, em que a } \\
\text { graduação passa a constituir-se numa etapa de formação inicial no } \\
\text { processo contínuo de educação permanente; }\end{array}$ \\
$\begin{array}{l}\text { Propor uma carga horária mínima em horas que permita a flexibilização } \\
\text { do tempo de duração do curso de acordo com a disponibilidade e esforço } \\
\text { do aluno; }\end{array}$ \\
$\begin{array}{l}\text { Otimizar a estruturação modular dos cursos com vistas a permitir um } \\
\text { melhor aproveitamento dos conteúdos ministrados, bem como, a } \\
\text { ampliação da diversidade da organização de cursos, integrando a oferta } \\
\text { de cursos sequenciais, previstos no inciso I do artigo 44 da LDB; }\end{array}$ \\
\hline $\begin{array}{l}\text { Contemplar orientações para as atividades de estágio e demais atividades } \\
\text { que integrem o saber acadêmico à prática profissional, incentivando o } \\
\text { reconhecimento de habilidades e competências adquiridas fora do } \\
\text { ambiente escolar; }\end{array}$ \\
\hline $\begin{array}{l}\text { Contribuir para a inovação e a qualidade do projeto pedagógico do } \\
\text { ensino de graduação, norteando os instrumentos de avaliação. }\end{array}$ \\
\hline
\end{tabular}

Fonte: Resolução CNE/CP 1/2002, s/p (Síntese e grifos de Matias, 2017)

Observamos, portanto, que essas orientações pressupõem atividades práticas durante a integralização do curso. Dentre os princípios elencados, há certa preocupação com a "formação geral", com os "desafios de renovadas condições de exercício profissional" e "variados tipos de formação". Essas palavras do documento nos conduzem ao entendimento da necessidade de uma abordagem que vise ao desenvolvimento linguístico, mas também social. Também vale destacar que manter a mesma carga horária tanto para cursos com dupla licenciatura ou não, visando responder às exigências do mercado de trabalho, pode promover negligenciamento no currículo do curso. Portanto, observamos que a área de LE, na dupla licenciatura, perde espaço para a língua materna e suas literaturas, fator que pode inviabilizar projetos relacionados à diversidade cultural pertinentes à formação do professor de línguas.

No que tange aos objetivos e metas previstas nas DCN - FPEB, pressupõe-se desenvolver a capacidade de adaptar às demandas da sociedade, a fim de possibilitar o reconhecimento de habilidades e competências adquiridas fora do ambiente escolar. Tais pressupostos evidenciam a busca por desenvolver nos professores em formação, a habilidade

Gláuks: Revista de Letras e Artes-jan/jun. 2020 - Vol. 20, $N^{o} 1$ 
de negociar os entendimentos das relações culturais que permeiam tanto a sala de aula, como a comunidade e a visão do macro.

Para este estudo, é importante compreendermos o que as Diretrizes preveem para os cursos de graduação em Letras, a fim de percebermos o contexto em que a formação inicial de professores/as de línguas investigada acontece e, de modo geral, entender em que espaço a perspectiva crítica é cultivada. Nesse sentido, listamos também a estrutura flexível esperada para o curso e destacamos algumas das múltiplas competências que deveriam ser articuladas pelos indivíduos que estão cursando licenciatura dupla em Letras (Parecer $\mathrm{CNE} / \mathrm{CP} \mathrm{n}^{\circ} 9$ de 08/05/2001).

A estrutura organizacional deve:

$>$ Facultar ao profissional a ser formado opções de conhecimento e de atuação no mercado de trabalho;

$>$ Criar oportunidade para o desenvolvimento de habilidades necessárias para se atingir a competência desejada no desempenho profissional;

$>$ Dar prioridade à abordagem pedagógica centrada no desenvolvimento da autonomia do aluno;

> Promover articulação constante entre ensino, pesquisa e extensão, além de articulação direta com a pós-graduação;

> Propiciar o exercício da autonomia universitária, ficando a cargo da Instituição de Ensino Superior definições como perfil profissional, carga horária, atividades curriculares básicas, complementares e de estágio.

Com essa nova organização, o currículo começa a ser entendido como toda e qualquer atividade acadêmica que integra o curso e do professor passa-se a esperar o papel de orientador no que se refere aos conteúdos.

Quanto às competências, destacamos o mínimo exigido para a formação do/a professor/a de línguas, de acordo com as Diretrizes: “Ter domínio do uso da língua ou das línguas que sejam objeto de seus estudos, em termos de sua estrutura, funcionamento $e$ manifestações culturais ${ }^{4 \prime}$.

4 Grifos nossos. Texto disponivel em www.mec.gov.br/SESU/diretrizes.shtm 
Contudo, Paiva (2005, p. 349) acrescenta que além do domínio do uso da(s) língua(s), as competências mínimas deveriam ser as seguintes:

1 O domínio dos conteúdos básicos que são objeto dos processos de ensino e aprendizagem no ensino fundamental e médio;

2 O domínio dos métodos e técnicas pedagógicas que permitam a transposição dos conhecimentos para os diferentes níveis de ensino;

3 A capacidade de resolver problemas, tomar decisões, trabalhar em equipe e comunicar-se dentro da multidisciplinaridade dos diversos saberes que compõem a formação universitária em Letras.

Compreendemos, assim, que o documento alerta para a articulação das didáticas de cada conteúdo com as pesquisas que as embasam. Tendo em vista as metas em relação ao profissional, vale destacar a observância sobre os conteúdos: as Diretrizes postulam que "os estudos linguísticos e literários devem fundar-se na percepção da língua e da literatura como prática social e como forma mais elaborada das manifestações culturais ${ }^{5}$ ". (Parecer CNE/ $\mathrm{CP} \mathrm{n}^{\circ} 9$ de 08/05/2001)

Diante desse panorama histórico geral, torna-se fundamental compreender as especificidades do curso investigado, uma vez que os documentos consideram todas as atividades envolvidas como parte integrante do currículo. Assim, no próximo item, abordamos o perfil e a organização de um curso de Letras português/inglês da Universidade Estadual de Goiás.

\section{A licenciatura dupla em português/ inglês: um cenário goiano}

A Universidade Estadual de Goiás $^{6}$ é considerada uma das maiores universidades brasileiras em número de campi. O cenário escolhido para essa análise é o maior campus estadual em número de alunos em licenciatura. Entendemos que se trata de uma amostra significativa, uma vez que no Projeto Político do Curso (PPC) é acentuada a preocupação com a qualidade da formação por atuar com a "qualificação dos professores para trabalharem na Educação Básica, a fim de garantir aprendizagens essenciais à sua formação, possibilitando-

5 Idem.

6 Texto disponivel em http://www.ccseh.ueg.br/

Gláuks: Revista de Letras e Artes-jan/jun. 2020 - Vol. 20, $N^{o} 1$ 
lhes competências suficientes para difundir o desenvolvimento social, econômico e cultural da região".

A justificativa para a existência do curso encontrada no PPC se conecta à escolha deste câmpus para estudo. Ela enfatiza os princípios defendidos pelas DCN sobre "a formação da competência humana, com vista à construção de novos paradigmas para a cidadania", prevendo também um ensino que "deve transcender o tradicional espaço da sala de aula e articular-se com diferentes dimensões da realidade, instaurando, assim, novos papéis para os envolvidos no processo de formação". Esses elementos acentuam a problemática levantada nesta investigação, em relação à capacidade de negociar e questionar as aprendizagens para além da sala de aula, a fim de desenvolver habilidades múltiplas que possam tornar o aprendiz habilitado para lidar com as diferenças e semelhanças agindo com atitudes de respeito.

O curso de Letras português/inglês em análise apresenta em seu documento norteador, o PPC, um princípio que se baseia na implantação de propostas concretas que visem romper com o aligeiramento da formação apresentado pelas políticas educacionais. Observamos que isso se reflete na postura do professor que não segue um planejamento enrijecido, mas opta por respeitar o tempo de desenvolvimento dos aprendizes.

Nesse sentido, o PPC (2014, p. 16) traz como objetivo geral para o curso, além da capacitação para "utilizar as modalidades escrita e oral da língua portuguesa e da língua inglesa e reconhecer, analisar e interpretar os fatos linguísticos e literários nessas línguas”, formar docentes capazes de "transformar as práticas locais e recriá-las de acordo com as demandas surgidas em diversos contextos". Desse modo, há um convite para a perspectiva crítica, acenada por este estudo como meta a ser desenvolvida, com a finalidade de contribuir para mudanças sociais. Esse documento registra que para o curso

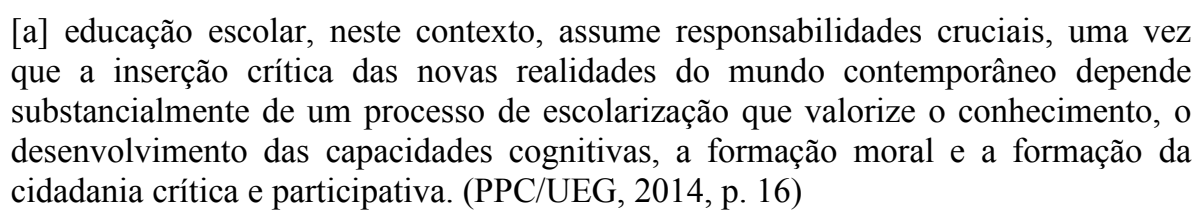

A ideia é que seja refletido sobre as diferenças que existe no universo dos professores/ as em formação inicial universitária no sentido de promover circunstâncias para transformálo. Para Pennycook (1990, p.43), devemos "assumir projetos políticos e morais [que rompam] com modos de investigação associais, apolíticos e a-históricos". 
Essa valorização da diversidade linguística e cultural e a necessidade de problematizar visões idealizadas na formação inicial universitária de professores/as figuram entre as metas estabelecidas para esse curso. Diante disso, entre os objetivos específicos, destacamos dois que consideramos refletir esse aspecto.

$>\quad$ Oferecer ao graduando em Letras uma formação direcionada para a sua atuação na Educação Básica, em termos de estrutura, funcionamento e manifestações culturais sobre os fatos da linguagem e sobre as diversas variedades e registros linguísticos;

$>\quad$ Promover a investigação teórica, científica, técnica e didático-pedagógica como forma de produzir e de divulgar conhecimentos científicos e culturais por meio da integração de atividades de ensino, pesquisa e extensão a da integração entre graduação e pós-graduação; (...). (PPC/UEG, 2014, p.17)

A análise do documento acena para a falta de uma estrutura curricular organizada para atender essa demanda de objetivos para a formação de docentes com uma atitude críticoreflexiva, que possibilite autonomia profissional. Por centrar nossa investigação na formação de professores/as de línguas, detalhamos algumas nuances referentes à organização curricular.

O Núcleo Específico é composto por três áreas que se desenvolvem em concomitância e ao longo do curso: a) estudos linguísticos de língua portuguesa; b) estudos linguísticos de língua inglesa; c) estudos literários. Essa distribuição deixa o estudo de língua inglesa com apenas um terço da carga-horária específica. Em consequência, torna-se evidente a necessidade de uma escolha metodológica que melhor oportunize o desenvolvimento dos objetivos de desenvolver habilidades linguísticas em relação ao idioma, mas também favorecer o desenvolvimento de uma consciência crítica, em adequação às condições de atuação.

Ademais, apesar da inclusão de componentes que envolvam as diferenças linguísticas e culturais no documento que rege o curso, como essas questões se interconectam no processo de formação de professores/as, para o desenvolvimento de perspectivas críticas.

O contexto de pesquisa é o curso de Letras português/inglês de um campus da UEG. Ao todo foram oito participantes, sete acadêmicos (Annogle, The guy, Sunshine, Assis, Glamil, Wade Wilson, Leiz Mascarenhas) e o professor Franklin. Os dados escolhidos para essa discussão são provenientes de gravação em vídeo, feita por um dos autores, a pesquisadora,

7 Conforme orientação ética de pesquisa, os participantes escolheram seus próprios pseudônimos 
que não é participante das atividades de sala, realizou a roda de conversa $(\mathrm{RC})$ ao final de uma aula.

\section{Articulação epistemológica: ecos da perspectiva crítica}

Embora o construto língua suscite discussões complexas e variadas, nos propomos a retomá-lo a partir de uma perspectiva crítica, como mencionado na sessão de abertura deste artigo, para que possamos analisar a fala dos participantes.

No que se refere à língua, Pennycook (2001) a considera um meio de produção e expressão daquilo que permeia a interação social. Nas palavras de Urzêda-Freitas e Pessoa (2012, p.232), "é uma ferramenta que produz e, ao mesmo tempo, reflete as relações socias". Nesse sentido, a língua, na perspectiva crítica, ultrapassa o sentido estrutural e interativo e passa a ser promotora de mudanças, capaz de subverter discursos coloniais e também, por outro lado, reprodutora de visões hegemônicas.

É preciso, portanto, evidenciar em ações políticas e culturais na formação universitária de professores/as de línguas uma perspectiva crítica de ensino, na busca por possibilitar aos aprendizes condições de problematizar as convenções linguísticas e culturais expressas nos textos em circulação dentro e fora da sala de aula.

Como mencionado, Pennycook (2001, p.112) defende que é preciso preparar os alunos para "resistir e modificar os discursos que constroem suas vidas". Para que isso seja possível, há que se avançar nos cursos de formação de professores/as de línguas com práticas que estimulem os cursistas a perceberem os sentidos ideológicos e dominantes que sobrecarregam os textos em produção e compreensão.

Portanto, vamos analisar um recorte interativo que é parte de uma roda de conversa (RC) realizada ao final de uma série de trabalhos de apresentação sobre comidas ao redor do

mundo. À medida que os participantes se integram à discussão, é possível observarmos uma visão crítica acerca do construto língua e do profissional que é formado no campus da UEG investigado:

Gláuks: Revista de Letras e Artes-jan/jun. 2020 - Vol. 20, $N^{o} 1$ 
1 Pesquisadora: Durante esta pesquisa, vocês apresentaram um trabalho sobre food. O que ficou mais evidente neste trabalho em relação ao aprendizado da língua inglesa?

2 Glamil: A gente conhece outras culturas através deste trabalho.

3 Wade Wilson: A gente faz uma viagem pelos países apresentados. Aprende sobre hábitos, fica muita coisa gravada. Fica marcado, você lembra da apresentação do colega também.

4 Pesquisadora: Além deste trabalho, a aula de língua inglesa é marcada por essa relação entre língua e cultura ou não? Há outros momentos em que se trabalha língua e cultura? Surgem atividades que propõem essa relação ou seria um trabalho constante?

5 Annogle: A cultura é um aspecto da língua. O jeito e o que você fala. Não tem como separar ela (a cultura) do ensino de línguas, ainda mais a língua estrangeira. O porquê de você querer aprender já determina o que você está querendo.

6 Pesquisadora: Vocês percebem que para ensinar língua eu preciso ensinar cultura ou posso ensinar língua mesmo sem trabalhar as questões culturais?

7 The Guy: Penso que são dois aspectos indissociáveis. É impossível falar de língua sem falar da cultura e falar da cultura sem falar de língua. Ainda mais a língua inglesa que vem carregada de um sentido de dominação cultural, ideológica, cronológica e financeira.

8 Annogle: Talvez se apresenta só o lado estrutural da língua, você perde muito nessa questão (ideológica)...Se você só trabalha a sintaxe. Ah, o verbo é aqui, o adjetivo é ali. Você perde muito.

9 Pesquisadora: Vocês poderiam me falar mais sobre os possíveis efeitos, no aprendente, de se trabalhar dessa forma no processo de ensinar línguas.

10 Sunshine: Eu acho que aluno se envolve mais//

11 Assis: O professor ganha mais ao trabalhar a língua atrelada à cultura. Porque assim você trabalha com o conteúdo (cultural). Então além de aprender a língua (estrutura) você está aprendendo o conteúdo, você ganha as duas coisas.

12 The Guy: Penso que forma um ser mais integrado à realidade, um ser humano mais completo. Se é que eu posso dizer humano mais completo. [AAA: risos]

13 The Guy: Mas a ideia é essa mesmo. Como as disciplinas, elas caminham para essa intencionalidade de formar o ser humano xxx, que não tenha ideia do todo, do completo. Quando você trabalha a língua atrelada à cultura e ela contextualizada você forma um cidadão, um ser humano mais integrado, realmente o que ele quer ser ...Qual é o perfil de professor que a universidade estadual quer formar? $\underline{\mathrm{O} \text { perfil }}$ que esta universidade forma é o perfil do profissional que vai atuar na educação básica, formando outros perfis de alunos e de sujeitos situados no tempo e no espaço, entendendo as diferenças do outro ou não ( $\mathrm{RC}-25 / 11 / 2015)$.

Embora um pouco extenso, o trecho acima é bastante representativo e corrobora nossa interpretação da concepção de indissociabilidade entre língua e cultura dos participantes. Apesar disso, dividi-lo descaracterizaria a fluidez da fala e do raciocínio típico da roda de conversa. $\mathrm{O}$ enfoque à relação mútua desses elementos e as possíveis vantagens de um ensino na perspectiva crítica intercultural são enfatizados na roda de conversa. Convém salientar que os alunos concordam que um ensino de língua que propõe um diálogo entre as culturas pode formar indivíduos mais bem preparados para lidar com a diversidade social. Compreendemos 
que a língua é vista como instrumento de luta e performatividade contra discursos e práticas hegemônicas (PENNYCOOK, 2001). Nesse sentido, defendemos que os programas e cursos de formação de professores/as de línguas precisam atentar para um currículo e a adoção de material didático relevantes quanto à interconexão entre língua e contexto sociocultural.

A própria documentação que rege a formação de professores/as de línguas já declara a exigência de domínio do uso da língua ou das línguas que sejam objeto de seus estudos, em termos de sua estrutura, funcionamento e manifestações culturais (BRASIL, 2012). Portanto, faz-se necessário desenvolver um trabalho que privilegie o entendimento de língua como prática social, que vem problematizar questões como a diversidade e a equidade, haja vista que "o conhecimento, como possiblidade de transformar relações sociais, se torna possível por meio da língua" (URZÊDA FREITAS; PESSOA, p. 232, 2012)

$\mathrm{Na}$ última fala do excerto acima, podemos notar certa inquietação de The Guy em relação ao perfil profissional desenvolvido no curso de Letras investigado. O PPC do curso também aponta preocupação com a qualidade da formação de professores, quando objetiva "possibilitar-lhes competências suficientes para difundir o desenvolvimento social, econômico e cultural da região" (PPC/UEG, 2014, p.13). Notamos como ações micro nas práticas pedagógicas podem exercer forças macro que podem oportunizar mudança, resistência e ação que geram autonomia na atuação docente e consequentemente, na formação de professores/as de línguas que possam transformar a sociedade (PENNYCOOK, p. 139, 2001).

\section{Considerações finais}

Analisar as políticas que norteiam o curso de Letras português/inglês em um campus da Universidade Estadual de Goiás nos permite observar certos avanços em relação à perspectiva crítica na formação universitária de professores/as de línguas. Dentre eles, identificamos indícios de postura crítica e reflexiva nos ecos discursivos dos participantes, no sentido de problematizar a formação que a instituição pretende oferecer. E ainda, avaliar que o ensino de línguas não pode estar dissociado às questões sociais e culturais. Essa postura ressoa uma preocupação em contemplar a diversidade linguística e cultural.

$$
\text { Gláuks: Revista de Letras e Artes-jan/jun. } 2020 \text { - Vol. 20, } N^{o} 1
$$


Outro ponto essencial é incluir essa visão crítica nas políticas, documentos e projetos que norteiam os cursos de licenciatura em Letras, haja vista a necessidade de envolver professores/as em formação universitária em um fazer pedagógico crítico, conectados à sensível oportunização de mudanças e transformação social.

\section{Referências bibliográficas}

BRASIL. Diretrizes Curriculares Nacionais: formação de professores da educação básica. Brasília: MEC, 2012.

. Orientações Curriculares Nacionais para o Ensino Médio. Brasília: MEC, 2006.

. Resolução $n^{\circ}$ 9. Formação pedagógica, de 10 de Outubro de 1969. Disponível em: http://cev.org.br/biblioteca/resolucao-n-9-10-outubro-1969/. Acesso em 10 abr. 2020

. Resolução Conselho Nacional de Educação/CP 1/2002. Disponível em:

www.mec.gov.br/cne/pdf/CP012002.pdf. Acesso em 10 abr. 2020

QUIJANO, A. Colonialidad y modernidad/racionalidad. Perú Indígena, v. 13, n. 29, p.11-20, 1992

MATIAS, D.S. Diálogos interculturais na aula de língua inglesa: um estudo de caso de cunho etnográfico. Dissertação. Mestrado Interdisciplinar em Educação, Linguagem e Tecnologias. Universidade Estadual de Goiás, 2017. 121p.

MOITA LOPES, L. P. Linguística aplicada e vida contemporânea: problematização dos construtos que têm orientado a pesquisa. In: MOITA LOPES, L. P. Por uma linguística aplicada indisciplinar. São Paulo, Parábola, 2006, p. 85-107.

PAIVA, V.L.M.O. O Novo Perfil dos Cursos de Licenciatura em Letras. In: TOMICH, et al. (Orgs.). A interculturalidade no ensino de inglês. Florianópolis: UFSC, 2005, p.345-363 (Advanced Research English Series).

PARECER Conselho Nacional de Educação, $\mathrm{n}^{\circ} 9$ de 02 de Maio de 2001. Disponível em: http://portal.mec.gov.br/component/content/article/323-secretarias-112877938/orgaosvinculados-82187207/12861-formacao-em-nivel-mediopara-a-docencia-na-educacao-basica.

PENNYCOOK, A. A critical applied linguistics: an introduction. Mahwah NJ, Lawrence Erlbaum Associates, 224p. 2001 
Posthumanist applied linguistics. Oxford and New York: Routledge. Colomb. Appl.

Linguist. J., 2018.

PESSOA, R. R. Formação de Professores/as em tempos críticos: reflexões sobre colonialidades e busca por um pensar decolonial. IN: MAGNO E SILVA, W.; SILVA, W. R.; CAMPOS, D. (Orgs) Desafios da formação de professores na linguística aplicada. Campinas, São Paulo: Pontes, 2019, p. 173-186

URZÊDA FREITAS, M.T.; PESSOA, R.R. Rupturas e continuidades na Linguística Aplicada Crítica: uma abordagem histotiográfica. Calidoscópio. Vol 10, n.2, p. 225-238, mai/ ago 2012. Doi:10.4013/cld 2012.102.09

\title{
Echoes from a critical perspective in the university formation of language teachers
}

\begin{abstract}
This article presents the analysis of a Portuguese / English Language course at the State University of Goiás, with the purpose of reflecting on the critical perspective in the university formation of language teachers. The study arises from some questions: what is a critical perspective in the training of language teachers? What is language conception for this perspective? do the documents that guide the course present elements aligned with the critical principles? what are the perception of teachers in university formation? Based on the assumption that it is essential to involve teachers in initial training in a critical pedagogical practice, connected to cultural and linguistic diversity, we seek to identify the policies that guide this course and understand how the principles of critical applied linguistics echo in the voices of the participants. In this sense, from a case study, we propose an articulation of these policies with the critical epistemology defended by Pennycook (2001, 2018) Pessoa (2019) and Urzêda-Freitas e Pessoa (2012). We understand that in order to think about a critical formation, it is necessary to start from a conception of language as an instrument of social transformation and this conception must be presented in the guiding documents, in the choices of texts and in praxis.
\end{abstract}

Key words: University formation, Critical perspective, Language teachers. 